\title{
What specific plant traits support ecosystem services such as pollination, bio-control and water quality protection in temperate climates? A systematic map
}

\author{
Claire J. Cresswell ${ }^{1 *} \mathbb{0}$, Heidi M. Cunningham² ${ }^{2}$ Andrew Wilcox ${ }^{1}$ and Nicola P. Randall ${ }^{1}$
}

\begin{abstract}
Background: Agricultural intensification has contributed to increased diffuse source pollution within water catchments, reduced heterogeneity within the landscape and caused major declines in farmland wildlife. This decrease in biodiversity has been shown to decrease vital ecosystem services such as pollination, biological pest control (biocontrol) and water quality protection. The morphological traits of plant species, such as floral display size and leaf area, provide support to these services and vegetative strips can be established with plants that have these desirable traits to try and restore ecosystem service support to farmland. Vegetative strips are widely used across the world, especially in Europe, however, there is a need to increase their functionality due to issues of land availability and food security. To do this, combinations of plant species that will support specific ecosystem services, have been developed. However, to enable a fully-informed development process, evidence must be collated on which specific plant traits provide the support to the target ecosystem services. The primary objective of this study was to systematically map all evidence for specific plant traits that may provide support for pollinators, bio-control and water quality protection in temperate climates.
\end{abstract}

Methods: Both published and grey literature were obtained through databases and NGO websites using key search terms. An initial 34,077 articles were identified with a total of 11,705 individual articles, after duplicates were removed. These were screened for inclusion based on criteria such as subject, climate and language. Each article was coded into a Microsoft Access database using generic (e.g. author, publication date, study length) and topic specific (e.g. target system, organism and ecosystem service) keywords.

Results: After screening 56 articles were coded into the systematic map. A total of 40 articles identified 37 plant traits for pollinator support, seven identified eight traits for bio-control and nine identified 26 for water quality protection. All articles were published between 1983 and 2017 and they included studies that were undertaken in 22 different countries.

Discussion: This systematic mapping process produced a searchable database of literature available on plant traits and the target ecosystem services. It has highlighted that more research has been conducted on plant traits for pollinator support than for bio-control and water quality protection, identifying potential research gaps in these areas. Evidence presented in this map could inform decisions related to the suitability of plant species for inclusion within multifunctional vegetative strips, providing targeted ecosystem services. This information could be used by policy makers to develop an option that could benefit landowners and farmland wild life concurrently.

Keywords: Pollinator, Beneficial invertebrate, Natural enemy, Buffer strip, Agri-environment scheme, Biodiversity, Multifunctional field margin, Vegetative strip

\footnotetext{
*Correspondence: ccresswell@harper-adams.ac.uk

1 Harper Adams University, Newport, Shropshire TF10 8NB, UK

Full list of author information is available at the end of the article
} 


\section{Background}

The intensification of agricultural practices since the 1940s has led to increased diffuse source pollution in farmland water catchments through cultivation, the use of pesticides and fertilisers and the removal of off-crop habitat $[1,2]$. These practices have been attributed to major declines in farmland wildlife, including wildflowers, invertebrates, mammals and birds [3-6]. Numerous reports have shown that a decline in farmland biodiversity can negatively affect the provision of multiple ecosystem services [7-9]. In particular pollination, biological control (bio-control) and water quality protection have been effected and evidence of this can be seen in global pollination deficits caused by pollinator declines (e.g. [10-13]) and in declines in water quality through pesticide, sediment, nitrate and phosphorus run-off and erosion (e.g. [14-16]), although riparian buffer strips could mitigate this pollution [17]. Also, as there are continuing reports of insecticide resistance since the 1990s (e.g. [18-20]), there is an increasing need to restore support for natural enemies used in bio-control [21-23].

To help mitigate some of these effects and develop more sustainable agricultural practices, semi-natural habitat resources that support pollinators, natural enemies and water quality protection, can be returned to farmland [24]. The morphological traits of specific plant species, such as nectar content, floral display size or leaf area [25], provide support for these services [26, 27]. For example, Bianchi and Wackers [28] showed that more parasitoids were attracted to plants with a higher nectar content, Kudo et al. [29] showed that a larger floral display size was preferred by Bombus hypocrita supsp. Sapproensis and Burylo et al. [30] showed that a plant's leaf area positively correlated with its ability to trap sediment.

A widely-used and effective method to re-establish these services within farmland is the sowing of plant mixtures outside of the cropped areas, such vegetative strips in field margins [31], and the inference is that these could be optimised if they were established using plant species with desirable traits. Policy support for this is already available through legislation and incentives across Europe. For example, within the European Union (EU), the Habitats Directive protects specific animals, plants and habitats [32], and the Water Framework and the Nitrates Directives protect water quality, the latter specifically addressing effects on water quality arising from the leaching of nitrates into watercourses on farmland [33]. In addition, the EU Common Agricultural Policy (CAP) provides funding to help preserve habitat biodiversity, enhance water quality and reduce soil erosion in the form of greening and agri-environment schemes [34-37].
These policies have been highly influential in the restoration of biodiversity and ecosystem services to farmland habitat [38]. Future land availability for these schemes is being increasingly restricted due to increased food production requirements which have been exacerbated by climate change, competition for land, and other pressures on land use [39, 40]. One recent potential solution to these issues is the sustainable intensification of agriculture, which often promotes the increase of food production from existing land whilst minimising pressure on the environment [41-43]. An approach within this solution is to increase the ecosystem service value of non-cropped areas on farmland by selecting the most supportive plant species for multiple ecosystem services [31, 44]. Supportive combinations of plant species have been investigated in parts of Europe (e.g. [45, 46]), but they have not considered which plant traits actually support the target ecosystem services.

Stakeholders from Syngenta UK Ltd are interested in developing vegetative strip seed mixes that they distribute to farmers. They have funded this work alongside the Biotechnology and Biological Sciences Research Council as part of a Ph.D. project to develop a multifunctional seed mix, based on scientific evidence. Discussions with stakeholders from the Game and Wildlife Conservation Trust and Fera Science Ltd encouraged a focus on plant traits as these are what define a plants ability to provide support for ecosystem services. Also, the initial ideas for the project arose from two previous systematic maps, one funded by Defra and the Natural Environment Research Council to investigate interventions to reduce water pollution [47] and one investigating interventions for enhancing farmland biodiversity [48]. In order to provide an evidence base to inform the design of future multifunctional non-cropped planted areas we systematically mapped all evidence on what specific plant traits provide support for ecosystem services including pollination, bio-control and water quality protection.

\section{Objective of the systematic map}

The primary objective of this systematic map was to collate existing research evidence on specific plant traits that may support pollinators and natural enemies and provide water quality protection. Studies undertaken in any type of habitat within temperate climate zones were included. A detailed summary of the nature and character of the evidence is presented alongside a summary of the specific plant traits that have been linked with the target ecosystem services. 


\section{Primary question}

Which plant traits provide support for the following ecosystem services, within temperate climates:

Pollination through pollinator support.

Bio-control through crop pest natural enemy support. Water quality protection?

\section{Elements of the primary question}

Population: Waterbodies, pollinator species and natural enemies of insect crop pests, within temperate climates. A temperate zone has a temperature range of $-3{ }^{\circ} \mathrm{C}$ to $+18^{\circ} \mathrm{C}$, shown as ' $\mathrm{C}$ ' in the Köppen-Geiger world map on climate classification Kottek et al. [49].

Exposure: Specific plant traits, for example floral display size or leaf area etc.

Comparator: Lack of traits or alternative traits, for example no floral display.

Outcome: Derived from studies that investigated any potential changes in the populations, for example, increased pollinator or natural enemy visits to a flower, improved water quality within a water body or reduced soil erosion.

\section{Methods}

The methods used in the development of the systematic map database were adapted from the Collaboration for Environmental Evidence (CEE) Systematic Review Guidelines [50] and from an existing systematic map report by Randall and James [48]. The detailed methods are presented in the protocol by Blowers et al. [51]. A summary of these methods and any deviations are presented here.

\section{Searches}

In November 2014, specific search term combinations with Boolean search operators were entered into multiple online databases to capture an un-biased sample of the relevant published and grey literature. The search terms were established as stated in the protocol [51]. In January 2017, the searches were updated to capture articles published after November 2014. For these updated searches the search terms stayed the same, but single search strings were used instead of multiple searches. This was the only deviation from the original methods stated in the protocol and did not change which articles may have been discovered by the searches. Full lists of search terms, strings and databases can be found in Additional files 1,2 and 3.

\section{Article screening and study inclusion}

The results from the searches were imported into an EndNote X7 library file and any duplicates removed.
The inclusion criteria were agreed prior to screening to ensure that only articles relevant to the objective were included in the systematic map.

\section{Inclusion criteria}

All retrieved studies were assessed for relevance using the following inclusion criteria:

Relevant subject(s): Studies that investigated some aspect of plant traits and how they could provide support for the target ecosystem services were considered for inclusion into the systematic map.

Relevant climate zone: Studies that had been undertaken in a region with a temperate climate, i.e. those classified as ' $C$ ' in Kottek et al. [49].

Language: All searches were conducted in English, however any article that was found in another language was also included in the initial searches. Only studies published in English were included in full text assessment, due to limited resources and the languages known by the study reviewers.

Date: No date restrictions were applied to initial searches, however the update searches restricted the date to articles published after November 2014.

Relevant ecosystem service provided: The following support for ecosystem services provided by plant traits were included: support for pollinators and crop pest natural enemies and water quality protection.

Relevant population: Water bodies, pollinator species and natural enemies of insect crop pests.

Relevant exposure: Specific plant traits, for example floral display size, leaf area, root length, plant height.

Relevant comparator: Lack of traits or alternative traits, for example no floral display.

Relevant outcome: Any study that investigated potential changes in the populations including:

- Effects on pollinator abundance and diversity, visitation rates and attractiveness.

- Effects on natural enemy abundance and diversity or predation rates.

- Effects on water quality in water bodies including inhibiting pollution from nitrogen, phosphorus, pesticides and sediment levels.

Relevant study design: Any primary research study that collected experimental or quasi-experimental data to investigate the effect of specific plant traits on provision of the named ecosystem services.

Article screening was undertaken by one reviewer at the title level. A second reviewer, that was blind to decisions made by the first reviewer, examined a random subset of $10 \%$ of the articles at abstract level and a kappa analysis showed a statistic of 0.836 demonstrating a very 
high level of agreement. Any disagreement was discussed and resolved by consensus. Any articles that passed the inclusion criteria at abstract level were then taken forward for full-text assessment by one reviewer. Each article was screened according to the inclusion criteria and any that did not meet the criteria were excluded, these can be found in Additional file 4. Review articles were not included but reference lists of relevant review articles were hand searched for potentially relevant primary research studies.

\section{Coding of articles and study data}

Studies from articles that passed the inclusion criteria after full-text assessment were imported into a Microsoft Access database and coded according to author, title, year of publication, reference type, study country, study region/state, study site, study dates, study length, study type, type of access and language. More specific terms were also used including type of ecosystem service, response organism/system, plant trait, target organism/ system, outcome and the critical assessment decisions on replication, sample selection and other sources of bias. All coding was undertaken by one reviewer and any queries were discussed with a second reviewer and a consensus decision made.

\section{Study critical assessment}

The critical assessment method was informed by the systematic review guidelines' hierarchy of evidence used in medicine and public health [52] and conservation [53]. A generic list of variables used by Haddaway et al. [54] were modified by the authors and combined with topicspecific quality measures. Terms including 'yes', 'partially' or 'not at all' were applied by one reviewer to each study based on degree of replication, sample selection methods and other sources of bias, as shown in Table 1. Any queries were discussed with a second reviewer and a consensus decision made.

For example, a well-replicated, randomised control trial with no obvious bias was categorised with the term 'yes' in all cases. No studies were excluded from the database based on the critical assessment criteria.

\section{The systematic map database}

A systematic map database was developed to describe the extent of the research in this field, see Additional file 5 . It was created in Microsoft Access and is searchable by topic and arranged according to the generic coding terms. Also, it was designed so that it may be arranged by the specific coding terms, providing detailed information on the plant traits described by the articles in the map and how they have been related to support for the target ecosystem services.

\section{Results}

\section{Summary of the evidence}

In total the searches in November 2014 and January 2017 identified 34,077 articles, with a total of 11,705 once duplicates were removed. These were screened for inclusion according to the schematic in Fig. 1.

Of the screened articles, 56 contained studies that met the inclusion criteria and were subsequently included in the systematic map database. All the included studies were from journal articles containing primary research. There were no relevant studies found for inclusion from the grey literature searches. Each article contained one relevant study, but some studies investigated multiple plant traits. In the systematic map database each row details one study, with each column providing further details e.g. 'Author', 'Study Site', 'Study Length' 'Plant Trait(s)' etc. In each cell a drop down menu shows the possible keyword options and indicates where multiple keywords have been chosen. For example, in the 'Plant Trait(s)' column the drop down menus indicate each of the traits that have been selected according to the evidence provided in the article. Each column can also be filtered according to the keywords included. For example, the 'Ecosystem Service' column can be filtered for articles that present evidence on one specific ecosystem service.

\section{Key findings of the systematic map}

Article publication dates ranged from 1983 to 2017, see Fig. 2 , and the vast majority $(n=47)$ of articles were published within the last $10-15$ years.

Table 1 Study critical assessment categories. Modified from Haddaway et al. [54]

\begin{tabular}{|c|c|c|c|}
\hline Critical assessment term applied & Replication & Sample selection & Other sources of bias \\
\hline Yes & Well-replicated (> 10 samples per group) & Random or blocked or exhaustive & None evident \\
\hline Partially & $\begin{array}{l}\text { Moderate level of replication (4-10 samples } \\
\text { per group) }\end{array}$ & Not stated but clearly random or blocked & Potential confounder \\
\hline Not at all & $\begin{array}{l}\text { Poorly-replicated or not stated (1-3 samples } \\
\text { per group) }\end{array}$ & Purposive or not stated & Clear confounder \\
\hline
\end{tabular}




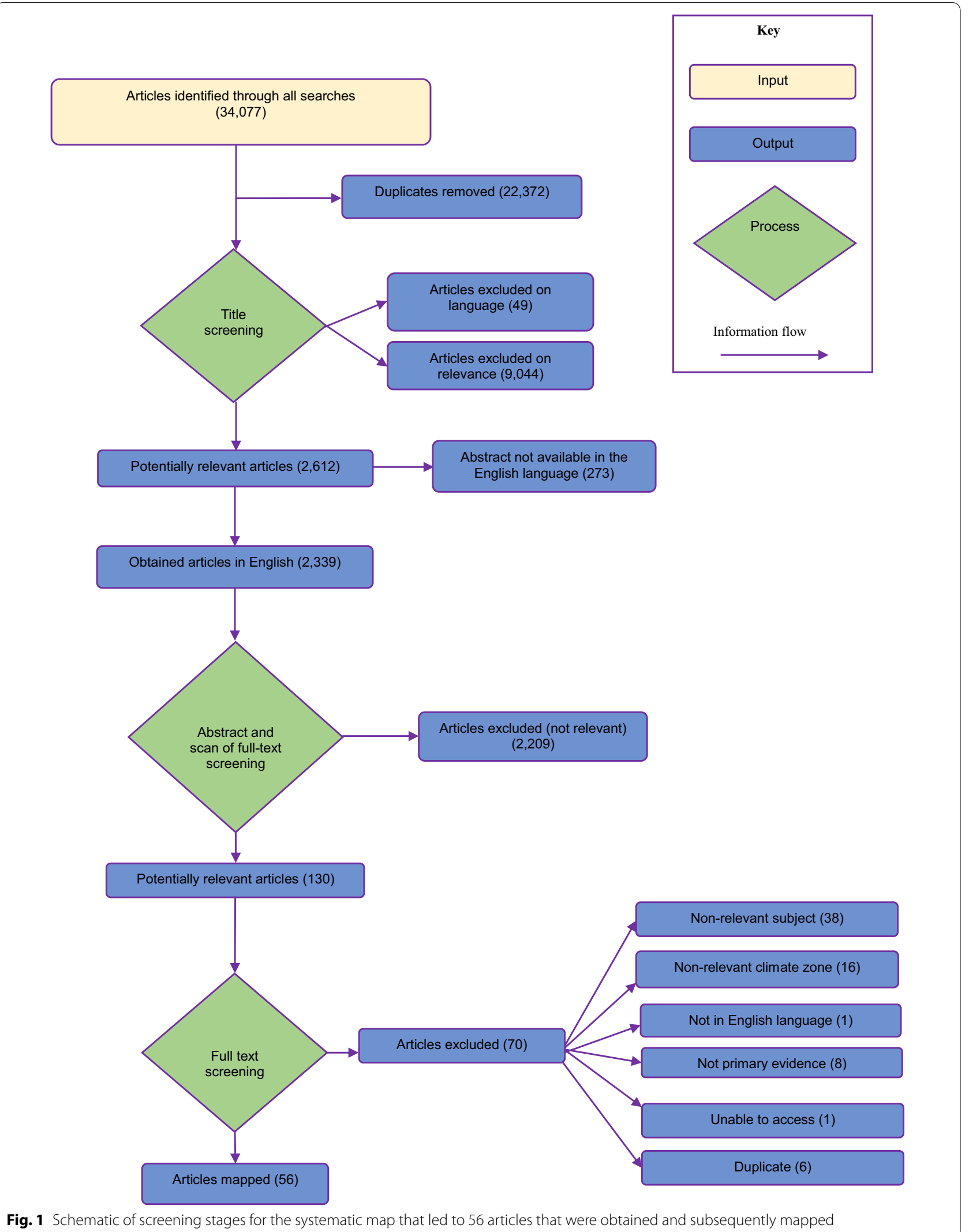




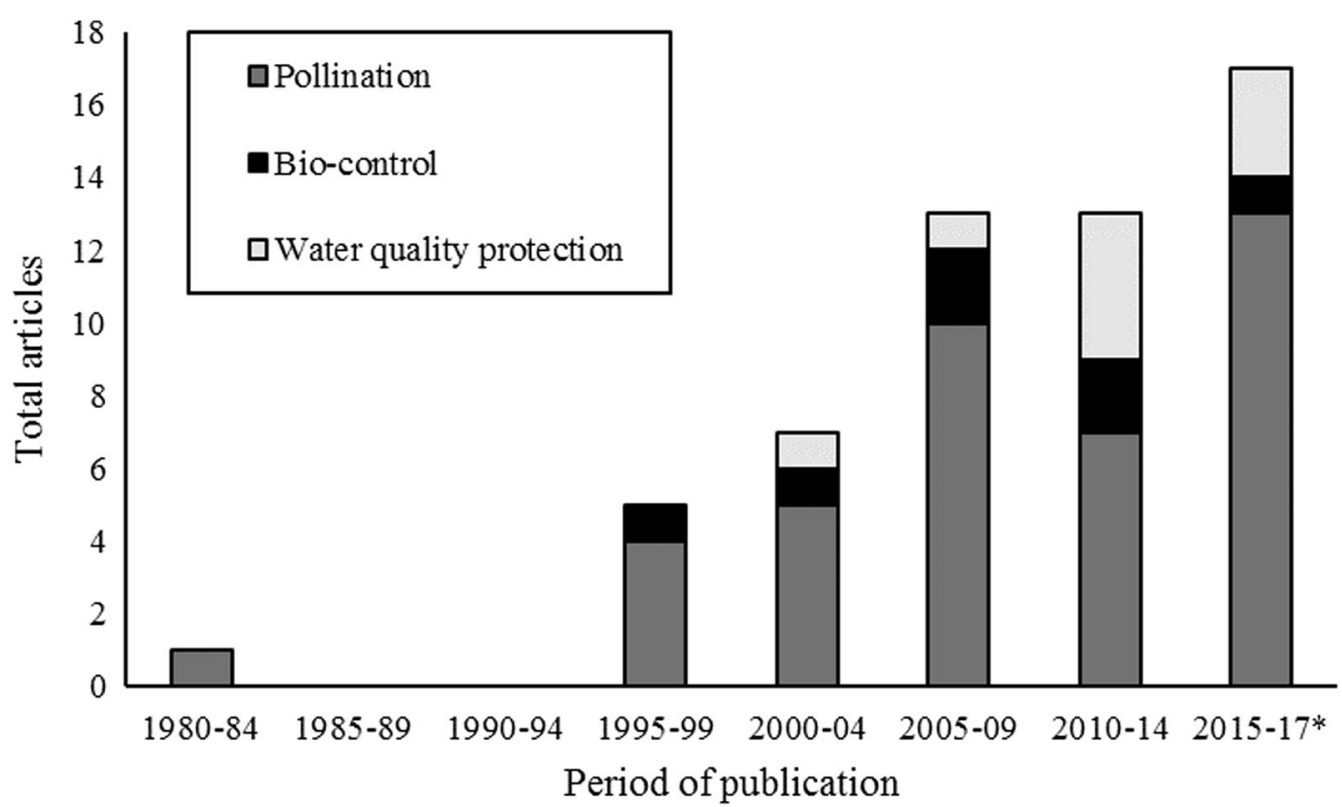

Fig. 2 The total articles published in each 5 year period from 1980, for each target ecosystem service.* Note that this period is 2 years shorter than the others

Studies from these articles were performed in a wide variety of countries, see Fig. 3, however there were no studies from Eastern Europe and the most studies were undertaken in the USA $(\mathrm{n}=12)$.

The decisions made in the critical assessment are displayed in Fig. 4. A total of 45 studies showed moderate to high replication with at least four samples per group, 43 showed randomised sample selection and 49 showed no other evident sources of bias using our critical assessment method. Decisions were not possible if the relevant information for the assessment criteria could not be accessed.

\section{Plant traits and ecosystem services}

For each article information on the studied plant traits was coded into the systematic map database. This included the plant trait (e.g. floral display size), the response organism or system that was monitored (e.g. plant species), the target organism (e.g. pollinator species), the outcome of the study (e.g. increased visitation) and the ecosystem service it was linked with (e.g. pollination).

Out of the 56 articles that were included in the systematic map, 40 related to pollination (through pollinator support), seven related to bio-control (through crop pest natural enemy support) and nine related to water quality protection. The specific plant traits and the ecosystem service(s) that they were related to in these articles are shown in Table 2. In total, 68 plant traits were studied.
With regards to pollinator support, 33 of the plant traits were related to the flower of a plant, three were related to the leaf and one to the stem. Also, six traits studied to support natural enemies were related to the flower of the plant, two to the leaf and one to the stem. In contrast, three traits studied to support water quality protection were related to the leaf of the plant, 17 were related to the roots and five to the plant as a whole.

The nine articles found for water quality protection studied 26 individual plant traits, 18 of which related to the roots of a plant. The 40 articles found for pollination studied 37 individual plant traits that related to pollinator support. Nineteen of which related to the floral display of the plant, for example floral display size $(n=11)$ and flower colour $(n=9)$. The seven articles found for bio-control studied eight individual plant traits that were related to support for crop pest natural enemies. Furthermore, floral display size, flower colour and flower nectar were all investigated in studies relating to pollinator support and natural enemy support.

\section{Discussion}

The aim of this systematic map was to discover evidence on specific plant traits in relation to pollination, bio-control and water quality protection within the literature. In light of this, we discuss the key findings made by the systematic map in relation to each ecosystem service and any potential limitations to the map. 


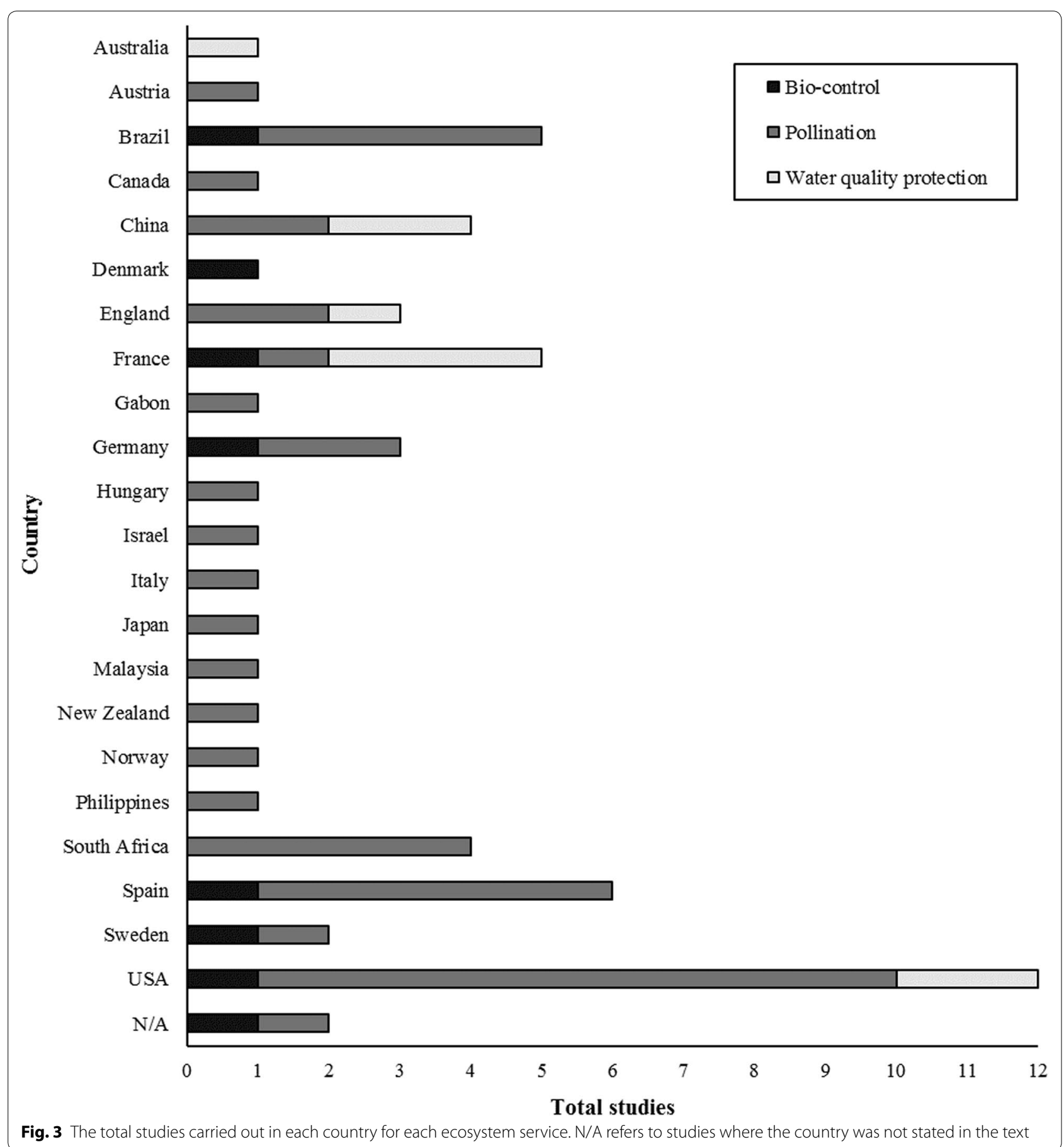

\section{Key findings}

This systematic map collated evidence on specific plant traits and how they may support the target ecosystem services. Due to the specificity of the inclusion criteria, just 56 articles were suitable for inclusion within the map. According to our critical assessment method, over half of the articles included studies that demonstrated moderate to high replication, randomised sample selection and no other source of bias. The publication dates of the articles span 34 years, with 41 published within the last 12 years, showing a recent increase in the volume of research in this topic area. A total of 68 plant traits were studied and related to the support of the target ecosystem services, spanning the entire plant anatomy. 

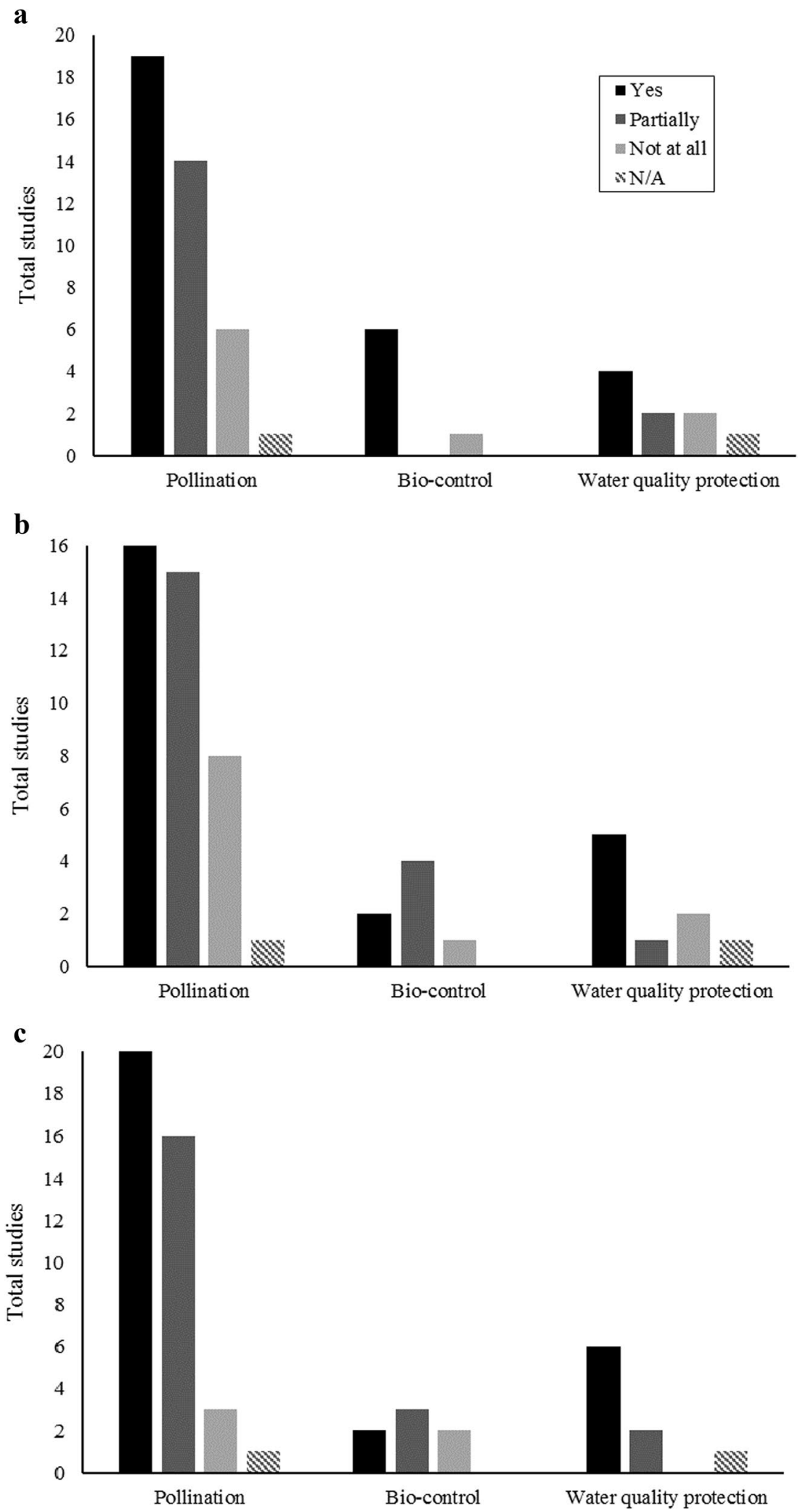

Fig. 4 Decisions made in the critical assessment of studies according to $\mathbf{a}$ degree of replication, $\mathbf{b}$ sample selection methods and $\mathbf{c}$ other sources of bias. N/A denotes the studies where a decision was not possible 
Table 2 Plant traits and related ecosystem services investigated in the literature

\begin{tabular}{|c|c|c|c|c|}
\hline \multirow[t]{2}{*}{ Plant anatomy section } & \multirow[t]{2}{*}{ Plant trait } & \multicolumn{3}{|c|}{ Ecosystem service } \\
\hline & & Pollination & Bio-control & Water quality protection \\
\hline \multirow[t]{36}{*}{ Flower } & Achromatic component & $\checkmark$ & & \\
\hline & Anthers & $\checkmark$ & & \\
\hline & Anthesis & $\checkmark$ & & \\
\hline & Availability of nectar & & $\checkmark$ & \\
\hline & Bloom intensity & $\checkmark$ & & \\
\hline & Bract size & $\checkmark$ & & \\
\hline & Calyx width & $\checkmark$ & & \\
\hline & Chromatic component & $\checkmark$ & & \\
\hline & Colour stimulus & $\checkmark$ & & \\
\hline & Disc floret area & $\checkmark$ & & \\
\hline & Distyly & $\checkmark$ & & \\
\hline & Diurnal anthesis & & $\checkmark$ & \\
\hline & Floral display size & $\checkmark(11)$ & $\checkmark$ & \\
\hline & Floral nectar & $\boldsymbol{J}(3)$ & $\boldsymbol{J}(2)$ & \\
\hline & Floral odour & $\checkmark(4)$ & & \\
\hline & Floral scent & $\checkmark$ & & \\
\hline & Floral symmetry & $\checkmark$ & & \\
\hline & Floral thermogenesis & $\checkmark$ & & \\
\hline & Floral tubes & $\checkmark$ & & \\
\hline & Floral UV reflectance & $\checkmark$ & & \\
\hline & Flower colour & $\boldsymbol{J}(9)$ & $\checkmark$ & \\
\hline & Flower number & $\checkmark$ & & \\
\hline & Flower orientation & $\checkmark$ & & \\
\hline & Flower radial symmetry & & $\checkmark$ & \\
\hline & Flower shape & $\sqrt{ }(3)$ & & \\
\hline & Flower size & $\boldsymbol{J}(2)$ & & \\
\hline & Flower venation & $\checkmark$ & & \\
\hline & Nectar guides & $\boldsymbol{J}(2)$ & & \\
\hline & Number of open flowers & $\checkmark$ & & \\
\hline & Petal width & $\boldsymbol{J}(2)$ & & \\
\hline & Pollen quantity & $\checkmark$ & & \\
\hline & Pollen reward & $\checkmark$ & & \\
\hline & Spadices heat generation & $\checkmark$ & & \\
\hline & Spur length & $\checkmark$ & & \\
\hline & Stamen condition & $\checkmark$ & & \\
\hline & Total capitulum area & $\checkmark$ & & \\
\hline \multirow[t]{8}{*}{ Leaf } & Epicuticular wax & & $\checkmark$ & \\
\hline & Leaf area & & & $\sqrt{ }(5)$ \\
\hline & Leaf biomass & & & $\checkmark$ \\
\hline & Leaf gelsemine & $\checkmark$ & & \\
\hline & Leaf trichome & & $\checkmark$ & \\
\hline & Number of leaves & & & $\checkmark$ \\
\hline & Resin gland size & $\checkmark$ & & \\
\hline & Staminal hairs & $\checkmark$ & & \\
\hline Stem & Stalk length & $\checkmark$ & & \\
\hline \multirow[t]{3}{*}{ Root } & Belowground biomass & & & $\checkmark$ \\
\hline & Fibrous root diameter & & & $\checkmark$ \\
\hline & Fibrous root length & & & $\checkmark$ \\
\hline
\end{tabular}


Table 2 continued

\begin{tabular}{|c|c|c|c|c|}
\hline \multirow[t]{2}{*}{ Plant anatomy section } & \multirow[t]{2}{*}{ Plant trait } & \multicolumn{3}{|c|}{ Ecosystem service } \\
\hline & & Pollination & Bio-control & Water quality protection \\
\hline & Fibrous root surface & & & $\checkmark$ \\
\hline & Percentage fine roots & & & $\boldsymbol{J}(3)$ \\
\hline & Root area & & & $\checkmark$ \\
\hline & Root biomass & & & $\boldsymbol{J}(2)$ \\
\hline & Root density & & & $\checkmark$ \\
\hline & Root diameter & & & $\checkmark$ \\
\hline & Root length & & & $\boldsymbol{J}(3)$ \\
\hline & Root length density & & & $\checkmark$ \\
\hline & Root mass & & & $\boldsymbol{J}(2)$ \\
\hline & Root slenderness & & & $\checkmark$ \\
\hline & Root surface & & & $\checkmark$ \\
\hline & Root system density & & & $\checkmark$ \\
\hline & Root system topology & & & $\checkmark$ \\
\hline & Root tensile strength & & & $\boldsymbol{J}(2)$ \\
\hline & Rooting depth & & & $\checkmark$ \\
\hline \multirow[t]{5}{*}{ Whole plant } & Aboveground biomass & & & $\checkmark$ \\
\hline & Canopy density & & & $\boldsymbol{J}(2)$ \\
\hline & Height & & & $\checkmark$ \\
\hline & Plant biomass & & & $\checkmark$ \\
\hline & Plant roundness & & & $\checkmark$ \\
\hline
\end{tabular}

Numbers in brackets indicate where more than one article studied the plant trait

\section{Pollination through pollinator support}

As the overwhelming majority of these articles studied plant traits linked with pollination through pollinator support $(n=40)$, this shows a clear bias in the research. This bias is to be expected due to the highly dependent, mutualistic relationship between flowering plants and pollinators and current pollinator declines are driving further research to try and understand this relationship $[8,55,56]$. Interestingly, studies that showed traits relevant for pollinator support were the most numerous from the USA $(n=9)$ followed by Spain $(n=5)$, Brazil $(n=4)$ and South Africa $(n=4)$. This could be due to the size of the country (both land mass and population) and the large proportion of it that is within a temperate climate zone [49]. Also the articles that studied pollination through pollinator support were published from 1983 to 2016, indicating that research on how plant traits support pollinators has been carried across 33 years at least. It was also noted that the majority of plant traits that were studied for pollinator support, related to some aspect of the flower of a plant, in particular the floral display size ( $\mathrm{n}=11)$ and flower colour $(\mathrm{n}=9)$, and the traits that related to the flower varied greatly.

\section{Bio-control through crop pest natural enemy support}

A total of eight individual plant traits for bio-control through crop pest natural enemy support were studied by seven articles. This small number of articles indicates that there is a knowledge gap in this area. The studies were undertaken across Europe and North and South America, with one study undertaken in each of the following countries: Brazil, Denmark, France, Germany, Spain, Sweden and USA. This high variation in study country origin reduces any effects if bias on the information presented by the systematic map. Also, the publication dates for articles that studied bio-control through natural enemy support ranged from 1998 to 2015, showing that research in this area started 16 years after similar research for pollinator support. The plant traits that were studied related to the flower (6) and leaf (2) of a plant. This indicates that only above ground plant traits have been studied or identified in relation to the support of natural enemies. Also there was a cross-over between plant traits that were studied for natural enemy and pollinator support because floral display size, floral nectar and flower colour were researched for both. 


\section{Water quality protection}

Similar to bio-control, only nine articles studied plant traits and how they may support water quality protection, however, they did look into 23 individual traits. Over a third of these studies were undertaken in Europe [France $(\mathrm{n}=3)$ and England $(\mathrm{n}=1)]$, with the remaining studies spread across China $(\mathrm{n}=2)$, USA $(\mathrm{n}=2)$, and Australia $(\mathrm{n}=1)$. Also, water quality protection plant traits were studied slightly more recently than the other two ecosystem services with publication dates ranging from 2000 to 2017. Although three articles studied leaf traits and five studied whole plant traits for water quality protection, 18 traits were related to plant roots. This showed an overwhelming focus in the research on below ground traits for the support of this ecosystem service.

\section{Limitations to the searches}

As only articles available in English could be included in the map, this may have biased the studies included to only those that are from English speaking countries. There were over 20 articles that provided some valuable information on support for the target ecosystem services, but these were excluded because they studied plant community traits rather than individual plant traits. These types of traits are more complex and were not relevant for this systematic map.

Although access to article full-text can be a limitation to a systematic map, only one article had to be excluded on this basis.

Limited time and funding meant that the initial title screening was undertaken by one reviewer and this may have introduced a bias at this stage. Only one reviewer conducted the critical assessment of the studies presented by the articles, so in order to avoid a potential limitation to the map, no articles were excluded based on the decisions made.

\section{Conclusion}

This systematic map identified and coded 56 articles that could answer the primary question "What specific plant traits support ecosystem services such as pollination, bio-control and water quality protection in temperate climates?". It highlighted that over 68 plant traits have been studied, spanning the entire plant anatomy. It also identified a large bias in the research towards plant traits for pollinator support.

\section{Implications for research}

It is recommended that more primary research is undertaken on plant traits that may potentially support natural enemies or water quality protection. This research should aim to identify any other influential plant traits but also test those that have been identified so far, to develop the evidence base. A review of the study findings from the articles in this map could help investigate exactly how each of the plant traits may support the ecosystem services that they have been related to and this could provide recommendations for any further primary research that should be undertaken.

\section{Implications for policy and management}

The evidence collated so far could inform policy makers and land-owners on the design of vegetative strips to support pollination, bio-control and water quality protection. If such evidence-informed decisions are made, the efficacy of vegetative strips to support ecosystem services could be improved, providing benefits to the land-owner and farmland wildlife concurrently.

\section{Additional files}

Additional file 1. Keywords and qualifiers to be used in the literature search.

Additional file 2. Searches conducted to find articles published after November 2014.

Additional file 3. Databases searched for published and grey literature.

Additional file 4. List of articles and reasons for exclusion at full-text screening.

Additional file 5. Systematic map database.

\section{Authors' contributions}

CJC undertook the searches, screening, critical assessment and coding of the articles and drafted the systematic map report. HMC participated in the drafting and revision of the manuscript. AW provided technical support and reviewed the manuscript drafts. NPR conception of project and design of protocol methodology, involved in drafting and revision of manuscript, final approval of version. All authors read and approved the final manuscript.

\section{Author details}

${ }^{1}$ Harper Adams University, Newport, Shropshire TF10 8NB, UK. ${ }^{2}$ Syngenta, Jealott's Hill, International Research Centre, Bracknell, Berkshire RG42 6EY, UK.

\section{Acknowledgements}

The authors wish to thank those who commented on a previous draft of the manuscript. Harper Adams University provided access to the library databases.

\section{Competing interests}

The authors declare that they have no competing interests. Any reviewers involved in this review that are also authors of relevant articles will not be included in the decisions connected to the inclusion and critical appraisal of the articles.

Availability of data and materials

All data generated or analysed during this study are included in this published article and Additional files.

\section{Consent for publication}

Not applicable.

Ethics approval and consent to participate Not applicable. 


\section{Funding}

This systematic map is funded through a Ph.D. Studentship provided by the Biotechnology and Biological Sciences Research Council and Syngenta Ltd, Grant Number BB/M503411/1.

\section{Publisher's Note}

Springer Nature remains neutral with regard to jurisdictional claims in published maps and institutional affiliations.

Received: 7 August 2017 Accepted: 5 January 2018 Published online: 09 April 2018

\section{References}

1. Robinson RA, Sutherland WJ. Post-war changes in arable farming and biodiversity in Great Britain. J Appl Ecol. 2002;39:157-76.

2. Ehrlich PR, Ehrlich AH. Can a collapse of global civilization be avoided? Proc R Soc B. 2013;280:20122845.

3. Benton TG, Vickery JA, Wilson JD. Farmland biodiversity: is habitat heterogeneity the key? Trends Ecol Evol. 2003;18:182-8.

4. Donald PF, Green RF, Heath MF. Agricultural intensification and the collapse of Europe's farmland bird populations. Proc R Soc B. 2001;268:25-9.

5. Flowerdew JR. Mammal biodiversity in agricultural habitats. In: Kirkwood $\mathrm{RC}$, editor. Biodiversity and conservation in agriculture: proceedings of an international symposium organised by the British Crop Protection Council. 1997. p. 25-40.

6. Sotherton NW, Self MJ. Changes in plant and arthropod diversity on lowland farmland: an overview. In: Aebischer NJ, Evans AD, Grice PV, Vickery JA, editors. The ecology and conservation of lowland farmland birds. Oxford: Blackwell Scientific Publications; 2000. p. 26-35.

7. Zavaleta ES, Pasari JR, Hulvey KB, Tilman GD. Sustaining multiple ecosystem functions in grassland communities requires higher biodiversity. Proc Natl Acad Sci. 2010;107:1443-6.

8. Hector A, Bagchi R. Biodiversity and ecosystem multifunctionality. Nature 2007:448:188-90

9. Tilman $\mathrm{D}$, Reich $\mathrm{PB}$, Knops JM. Biodiversity and ecosystem stability in a decade-long grassland experiment. Nature. 2006;441:629-32.

10. Biesmeijer JC, Roberts SPM, Reemer M, Ohlemüller R, Edwards M, Peeters T, Schaffers AP, Potts SG, Kleukers R, Thomas CD, Settele J. Parallel declines in pollinators and insect-pollinated plants in Britain and the Netherlands. Science. 2006:313:351-4.

11. Kevan PG, Phillips TP. The economic impacts of pollinator declines: an approach to assessing the consequences. Conserv Ecol. 2001:5:8.

12. Kremen C, Williams NM, Thorp RW. Crop pollination from native bees at risk from agricultural intensification. Proc Natl Acad Sci USA. 2002;99:16812-6.

13. Garratt MP, Truslove CL, Coston DJ, Evans RL, Moss ED, Dodson C, Jenner N, Biesmeijer JC, Potts SG. Pollination deficits in UK apple orchards. J Pollinat Ecol. 2014;12:9-14

14. Kuivila KM, Foe CG. Concentrations, transport and biological effects of dormant spray pesticides in the San Francisco Estuary, California. Environ Toxicol Chem. 1995:14:1141-50.

15. Thorburn PJ, Biggs JS, Weier KL, Keating BA. Nitrate in ground waters of intensive agricultural areas in coastal Northeastern Australia. Agric Ecosyst Environ. 2003;94:49-58.

16. Tang W, Zhang H, Zhang W, Shan B, Zhu X, Song Z. Dynamics of heavy metals and phosphorus in the pore water of estuarine sediments following agricultural intensification in Chao Lake Valley. Environ Sci Pollut Res. 2015;22:7948-53.

17. Reichenberger S, Bach M, Skitschak A, Frede H-G. Mitigation strategies to reduce pesticide inputs into ground- and surface water and their effectiveness; a review. Sci Total Environ. 2007;384:1-35.

18. Green MB, LeBaron HM, Moberg WK. Managing resistance to agrochemicals: from fundamental research to practical strategies. Washington: American Chemical Society; 1990.

19. Bass C, Denholm I, Williamson MS, Nauen R. The global status of insect resistance to neonicotinoid insecticides. Pest Biochem Physiol. 2015;121:78-87.
20. Whalon ME, Mota-Sanchez D, Hollingworth RM. Analysis of global pesticide resistance in arthropods. In: Whalon ME, Mota-Sanchez D, Hollingworth RM, editors. Global pesticide resistance in arthropods. Oxfordshire: CABI International; 2008. p. 5-31.

21. Fiedler AK, Landis DA, Wratten SD. Maximizing ecosystem services from conservation biological control: the role of habitat management. Biol Control. 2008:45:254-71.

22. Gurr G, Wratten S, Barbosa P. Success in conservation biological control of arthropods. In: Gurr G, Wratten S, editors. Biological control: measures of success. Berlin: Springer; 2010. p. 105-32.

23. Rusch A, Chaplin-Kramer R, Gardiner MM, Hawro V, Holland J, Landis D, Thies C, Tscharntke T, Weisser WW, Winqvist C, Woltz M. Agricultural landscape simplification reduces natural pest control: a quantitative synthesis. Agric Ecosyst Environ. 2016;221:198-204.

24. Bommarco R, Kleijn D, Potts SG. Ecological intensification: harnessing ecosystem services for food security. Trends Ecol Evol. 2013;28:230-8.

25. Kattge J, Diaz S, Lavorel S, Prentice I, Leadley P, Bönisch G, Garnier E, Westoby M, Reich PB, Wright I. TRY_a global database of plant traits. Glob Change Biol. 2011;17:2905-35

26. Díaz S, Lavorel S, de Bello F, Quétier F, Grigulis K, Robson TM. Incorporating plant functional diversity effects in ecosystem service assessments. Proc Natl Acad Sci. 2007:104:20684-9.

27. Garnier E, Navas ML. A trait-based approach to comparative functional plant ecology: concepts, methods and applications for agroecology. A review. Agron Sustain Dev. 2012;32:365-99.

28. Bianchi F, Wackers FL. Effects of flower attractiveness and nectar availability in field margins on biological control by parasitoids. Biol Control. 2008;46:400-8

29. Kudo G, Ishii HS, Hirabayashi Y, Ida TY. A test of the effect of floral color change on pollination effectiveness using artificial inflorescences visited by bumblebees. Oecologia. 2007;154:119-28.

30. Burylo M, Dutoit T, Rey F. Species traits as practical tools for ecological restoration of marly eroded lands. Restor Ecol. 2014;22:633-40.

31. Hackett M, Lawrence A. Multifunctional role of field margins in arable farming. European Crop Protection Association, Cambridge Environmental Assessments, ADAS UK Ltd. 2014. http://www.ecpa.eu/sites/default/ files/Field\%20Margins\%20Arable\%20Farming_V02\%20(1).pdf. Accessed 25 Apr 2017.

32. European commission: environment-The Habitats Directive. 2016. http://ec.europa.eu/environment/nature/legislation/habitatsdirective/ index_en.htm. Accessed 25 Apr 2017.

33. European commission: environment-Introduction to the new EU Water Framework Directive. 2016. http://ec.europa.eu/environment/water/ water-framework/info/intro en.htm. Accessed 25 Apr 2017.

34. European commission: agriculture and biodiversity. 2017. http:// ec.europa.eu/agriculture/envir/biodiv/index_en.htm. Accessed $25 \mathrm{Apr}$ 2017.

35. European commission: agriculture and water. 2017. http://ec.europa.eu/ agriculture/envir/water/index_en.htm. Accessed 25 Apr 2017.

36. European commission: agriculture and pesticides. 2017. http://ec.europa. eu/agriculture/envir/pesticides/index en.htm. Accessed 25 Apr 2017.

37. European commission: soil and agriculture. 2017. http://ec.europa.eu/ agriculture/envir/pesticides/index en.htm. Accessed 25 Apr 2017.

38. Batáry P, Dicks LV, Kleijn D, Sutherland WJ. The role of agri-environment schemes in conservation and environmental management. Conserv Biol. 2015;29:1006-16

39. United Nations, Department of Economic and Social Affairs, population division: World population prospects, the 2015 Revision. 2015. http://esa. un.org/unpd/wpp/DataQuery/. Accessed 25 Apr 2017.

40. Godfray HC, Beddington JR, Crute IR, Haddad L, Lawrence D, Muir JF, Pretty J, Robinson S, Thomas SM, Toulmin C. Food security: the challenge of feeding 9 billion people. Science. 2010:327:812-8.

41. Garnett T, Godfray C. Sustainable intensification in agriculture. Navigating a course through competing food system priorities. Food Climate Research Network and the Oxford Martin Programme on the Future of Food. 2012. http://futureoffood.ox.ac.uk/sites/futureoffood.ox.ac.uk/files/ SI\%20report\%20-\%20final.pdf. Accessed 25 Apr 2017.

42. Garnett T, Appleby MC, Balmford A, Bateman IJ, Benton TG, Bloomer P, Burlingame B, Dawkins M, Dolan L, Fraser D, Herrero M. Sustainable intensification in agriculture: premises and policies. Science. 2013;341:33-4. 
43. Tittonell P. Ecological intensification of agriculture — sustainable by nature. Curr Opin Environ Sustain. 2014;8:53-61.

44. Stutter MI, Chardon WJ, Kronvang B. Riparian buffer strips as a multifunctional management tool in agricultural landscapes. J Environ Qual. 2012;41:297-303.

45. Syngenta. Grower's guidelines. Operation pollinator: multifunctional landscapes. 2014

46. Ecostac. Optimising ecosystem services in terms of agronomy and conservation. 2009. http://www.lancaster.ac.uk/lec/sites/ecostac/seed_selection.php. Accessed 25 Apr 2017.

47. Randall NP, Donnison LM, Lewis PJ, James KL. How effective are on-farm mitigation measures for delivering an improved water environment? A systematic map. Environ Evid. 2015;27(4):18.

48. Randall NP, James KL. The effectiveness of integrated farm management, organic farming and agri-environment schemes for conserving biodiversity in temperate Europe—a systematic map. Environ Evid. 2012;1:4.

49. Kottek M, Grieser J, Beck C, Rudolf B, Rubel F. World map of the KöppenGeiger climate classification updated. Meteorol Z. 2006;15:259-63.

50. Collaboration for Environmental Evidence: Guidelines for systematic review in environmental management. Version 4.2. 2013. http://www.
environmentalevidence.org/wp-content/uploads/2017/01/Reviewguidelines-version-4.2-final-update.pdf. Accessed 25 Apr 2017.

51. Blowers CJ, Cunningham HM, Wilcox A, Randall NP. What specific plant traits support ecosystem services such as pollination, bio-control and water quality protection in temperate climates? A systematic map protocol. Environ Evid. 2017;6:3.

52. Stevens A, Milne R. The effectiveness revolution and public health. In: Scalley G, editor. Progress in public health. London: Royal Society for Medicine Press; 1997. p. 197-225.

53. Pullin AS, Knight TM. Effectiveness in conservation practice: pointers from medicine and public health. Conserv Biol. 2001:15:50-4.

54. Haddaway NR, Styles D, Pullin AS. Evidence on the environmental impacts of farm land abandonment in high altitude/mountain regions: a systematic map. Environ Evid. 2014;3:17.

55. Nicolson SW, Wright GA. Plant-pollinator interactions and threats to pollination: perspectives from the flower to the landscape. Funct Ecol. 2017;31:22-5.

56. Potts SG, Biesmeijer JC, Kremen C, Neumann P, Schweiger O, Kunin WE. Global pollinator declines: trends, impacts and drivers. Trends Ecol Evol. 2010;25:345-53.

\section{Submit your next manuscript to BioMed Central and we will help you at every step:}

- We accept pre-submission inquiries

- Our selector tool helps you to find the most relevant journal

- We provide round the clock customer support

- Convenient online submission

- Thorough peer review

- Inclusion in PubMed and all major indexing services

- Maximum visibility for your research

Submit your manuscript at www.biomedcentral com/submit 